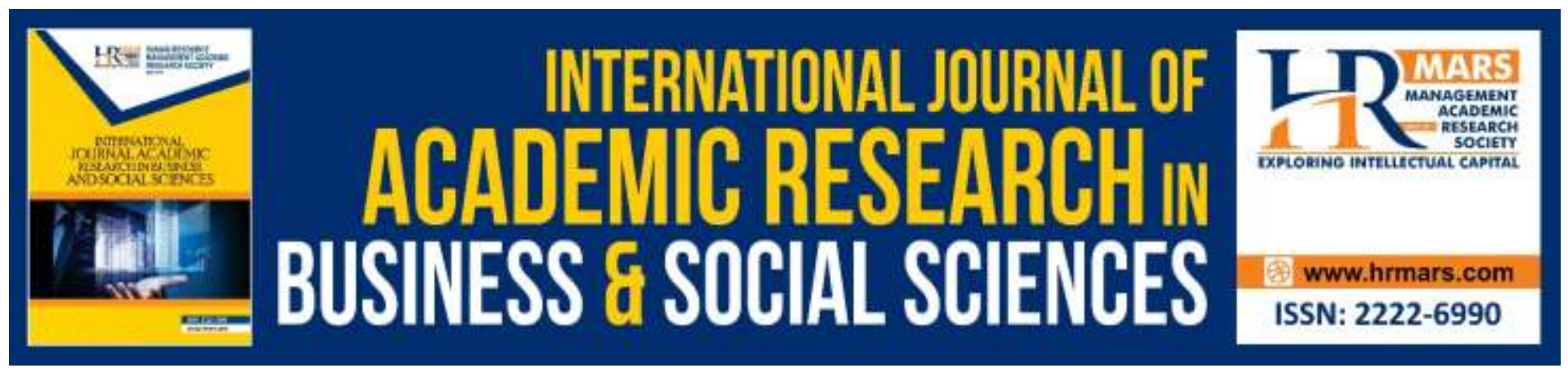

\title{
The Relationship Between Personality Traits and Job Satisfaction Among Secondary School Teachers in Putrajaya
}

Abdullah Khalid Salaudin, Mawarni Mohamed, Azlan Ahmad Kamal

To Link this Article: http://dx.doi.org/10.6007/IJARBSS/v9-i13/6870 DOI: $10.6007 /$ IJARBSS/v9-i13/6870

Received: 21 June 2019, Revised: 13 July 2019, Accepted: 22 August 2019

Published Online: 27 September 2019

In-Text Citation: (Salaudin et al., 2019)

To Cite this Article: Salaudin, A. K., Mohamed, M., \& Kamal, A. A. (2019). The Relationship Between Personality Traits and Job Satisfaction Among Secondary School Teachers in Putrajaya. International Journal of Academic Research in Business and Social Sciences, 9(13), 445-456.

Copyright: (C) 2019 The Author(s)

Published by Human Resource Management Academic Research Society (www.hrmars.com) This article is published under the Creative Commons Attribution (CC BY 4.0) license. Anyone may reproduce, distribute, translate and create derivative works of this article (for both commercial and non-commercial purposes), subject to full attribution to the original publication and authors. The full terms of this license may be seen at: http://creativecommons.org/licences/by/4.0/legalcode

Special Issue: Revolutionizing Education: Challenges, Innovation, Collaboration, 2019, Pg. 445 - 456 http://hrmars.com/index.php/pages/detail/IJARBSS JOURNAL HOMEPAGE

Full Terms \& Conditions of access and use can be found at http://hrmars.com/index.php/pages/detail/publication-ethics 


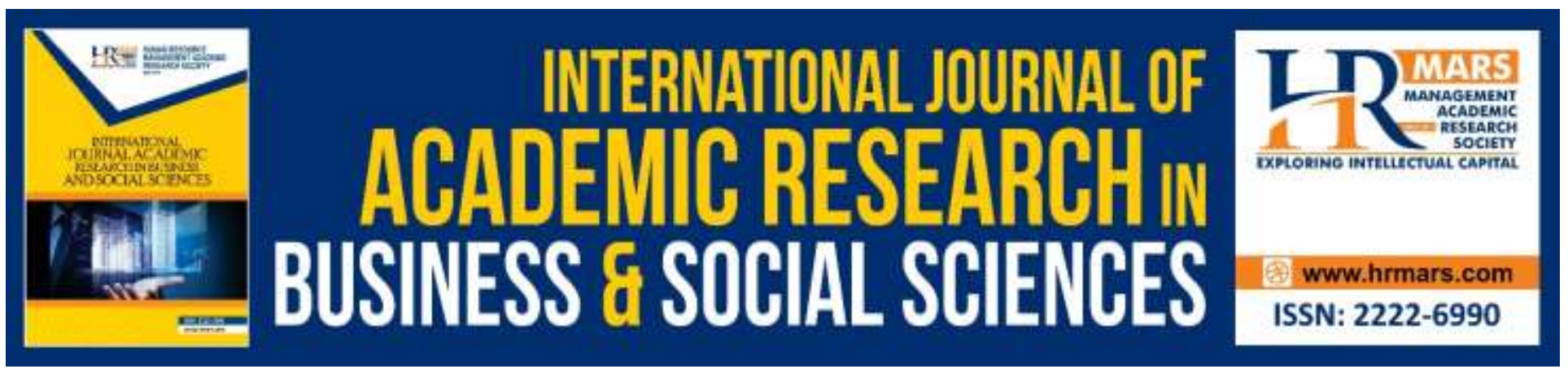

\title{
The Relationship Between Personality Traits and Job Satisfaction Among Secondary School Teachers in Putrajaya
}

\author{
Abdullah Khalid Salaudin, Dr Mawarni Mohamed, Dr Azlan Ahmad \\ Kamal \\ Faculty of Education, Universiti Teknologi MARA (UiTM), Selangor, Malaysia
}

\begin{abstract}
This research aims to investigate Putrajaya secondary school teacher's personality traits, to see the relations of personality traits to their feelings of satisfaction on their jobs, job satisfaction. The research on personality traits will be based on "The Big Five Model" (McCrae \& Costa, 1997) which illustrated the overall mean consists five sub variables: Agreeableness, Openness, Conscientiousness, Extroversion and Neuroticism. The findings in identifying the relationship between personality traits and job satisfaction is hoped to be beneficial to Ministry of Education (MOE) in planning for better strategies in implementing the Education Department Blueprint 2013-2025. The study highlighted the need of $\mathrm{MOE}$, especially the school administrators to give the correct job scope to teachers according to their personality traits other than from their skills and knowledge. The findings of the study would be beneficial to the school administrators, teachers and Ministry of Education in planning to improve their wok performance.
\end{abstract}

Keywords: Personality Traits, Big Five Model, Job Satisfaction

\section{Introduction}

Teaching profession in Malaysia has becoming more challenging as the world is getting more complex. Teachers must educate the students with knowledge that is needed in the world today, develop young minds with high order thinking skills, be objective and critical when giving ideas and accepting opinions. Teachers must instill moral values and equip the students with emotional stability, apart from assisting the students to live a healthy lifestyle complete with exercises and diet needed. This task has been highlighted in the National Education Philosophy to produce wholesome students who are ready for global challenges. This shows how teachers' responsibility has grown from the days they were hired to merely impart knowledge to the students till today where the teachers are responsible for the growth of the students in a whole

The Ministry of Education Report (1995) indicated that the human resource developed through better policies and educational systems is the strongest assurance in achieving Vision 2020. 
Accordingly, the Education Blue Print (2013 - 2025) indicated on the importance of developing high performing teachers in order to improve students' performance. In addition, it also highlights on the need to improve the quality and support to be provided to the school teachers and school leaders. Consequently, for the teachers to function efficiently and effectively, these teachers need to be truly satisfied with their own work. In relation to this, it is the responsibility of the Ministry of Education to provide the support needed by the teachers as only by providing the necessary support could help to improve their satisfaction towards their job and indirectly enable the government policy to be efficiently enacted and implemented. Teachers' satisfaction in doing their job is essential as highly motivated and committed teachers can also be one of the determining factors in developing wholesome and high-performance students who can face the challenges in the globalized world. Thus, students' performance and the development of wholesome students might not be highly attained if the teachers who are responsible for their teaching and learning do not feel satisfied with their own job. Due to the need to improve the teaching profession, the goal of this small-scale research is to better understand the correlation between job satisfactions with personality traits. By understanding this relationship, it would help to identify which personality is much easier to be satisfied or dissatisfied with their job. Please copy and paste your text here in this template for further editing

This might be used in selecting suitable individual to be teachers or in allocating suitable responsibilities for the present teachers that suits their personality. Accordingly, this chapter begins with discussion on the background and the problem statement of the study. Next, it highlights on the objectives of the research and the questions that the research aims to answer. Finally, it focuses on the significance, operational definition and the limitation of the study.

Weiss and Cropanzano (1996) define job satisfaction as the individual evaluation towards his or her job and work context. Job satisfaction is further defined as the individual's pleasant or optimistic emotional state or how content an individual is resulting from the appraisal of his or her own work experience. In the recent years, job satisfaction has been heavily researched and has also been a key research area for many specialists.

Researches have also indicated on the effect of personality traits on job satisfaction. The early theory on career choice and development has also stressed on job satisfaction as an important criteria in one's career. This is because the level of satisfaction could affect job's performance. In relation to this, the relationship of personality traits to the level of job satisfaction in any organization including schools need to be analyzed in order to retain particularly the productive and excellence workers. Moreover, suitable personality in the teaching profession could help to increase job satisfaction among the school teachers and to increase their job performance. In accordance, literature has also shown that teachers who do not have suitable personality and less interest towards own career as teachers could lead to less satisfaction towards teaching profession.

The research aims to investigate Putrajaya secondary school teacher's personality dimension that influenced their job satisfaction. 'The Big Five Model' (McCrae \& Costa, 1997) was used the measure the teachers' personality traits. The "Model" is essential and adequate in describing the basic aspects of normal personality (Mount \& Barrickm 1995)

This study was to investigate the relationship between job satisfaction and personality traits among secondary school teachers in Putrajaya. In addition, this study aims to examine the types of 
INTERNATIONAL JOURNAL OF ACADEMIC RESEARCH IN BUSINESS AND SOCIAL SCIENCES

Vol. 9, No. 13, Special Issue: Revolutionizing Education: Challenges, Innovation, Collaboration., 2019, E-ISSN: 2222-6990 @ 2019 HRMARS

personality, level of job satisfaction and identify the relationship of the Putrajaya secondary school teachers.

The findings of this study would greatly benefit the Ministry of Education including the school leaders and teachers. This study may be used by the Ministry of Education in planning for better strategies in implementing the Education Development Blueprint 2013 - 20125 such as in elevating teachers' professional development. Yin and Kwok (1996) stated that through a systematic professional development, teachers can acquire new skills, knowledge and attitudes that could improve or promote their teaching performance at various junctures of their careers. In accordance, the support provided by the governments together with teachers' positive commitment will lead to the achievement of the education's goal. This study could also highlight on the importance for teachers to know their own personality strengths and the factors that could increase their job satisfaction. High job satisfaction among teachers is necessary in developing students outcome as envisaged in the Education Development Blueprint as well as in achieving the National Education Policy. In accordance, Rubin (1985) indicated that, teaching styles adopted by teachers involve making choices and options and the choices they made would illustrate their perceived roles and images. Through this selected teaching style, teachers integrate the pedagogy or theories that they believe in and the teaching and learning practices that they choose to apply in their classroom. Therefore, the suitability between teaching styles and their personality traits could lead to their own job satisfaction.

\section{Literature Review and Theoretical Approach Job Satisfaction}

Due to its comprehensive nature, Paul E. Spector's (1997) definition of job satisfaction is one the famous definitions utilized in many studies. Nevertheless, this framework however, is theoretically insufficient to stand on its own. In order to ensure validity, other well-known theories could be incorporated into this framework. As discussed earlier, Maslow's Hierarchy of Needs and Herzberg's theory are the two most powerful theories that focus on hygiene factors and motivation. Spector (2000) also describes job satisfaction as the variables that affects one's feelings towards his own career. Job satisfaction is an extension of what is well-liked by the person in relation to his work and job dissatisfaction is an extension of what he did not like about his work.

Spector (1997) who focuses on the emotive factor critically discussed the way individual feel about their work and the many aspects and variables that lead to these feelings. These feelings are connected to the extent in which the employees enjoy or hate their work, which could be due to the emergence of the beneficiaries of job satisfaction in any given job conditions.

In studying the job satisfaction of academic staff in three universities in Malaysia, Santhapparaj and Shah Alam (2005) reported that there is a significant relation between job satisfaction and pay, promotion, fringe benefits, working condition, support of research and support of teaching. Nevertheless, they argued that the factors of fringe benefits and support of teaching had negative impact towards these academic staff job satisfactions. In addition, the female staffs were reported to have more satisfaction on their work compared to their male co-workers. Besides the possibility of enjoying their working environment, lower expectation towards salary and promotion might also be another reason for the female staff to be more satisfied than the male staff.

Personality Trait 
Personality traits has always been considered as one of the most important factors in predicting job performance. Personality traits is one of the behaviors that differentiates one person from another (Beer \& Brooks, 2011). It also provides insight on the specific job for the person. It will determine why some people who have same level of education, knowledge and skills but some can do better jobs than others (Sackett et.al. 2002). And if the personality traits are suited perfectly with the jobs they are doing, they are seen to be stable and steady throughout their work life (Denissenet.al., 2011: Gerber et.al., 2011; Myers, 1998)

Silverthorne (2004) meanwhile emphasized that there is no organization which shows a submissive or unchanging behavior and this is generated from the culture. Culture determines how perfect " $a$ person "fits" in a specific organization as the "fit" represents the feeling of comfort with that culture" (O' Reilly, 2004: 10). In an organization, this is directly associated with an employee's level of output production and in determining the level of employee turnover (Rousseau \& Parks, 1992; Ryan \& Schmit, 1996). Culture prevails in the organization to develop the customs for employee's behavior which effect P-O fit which in turn affects organizational output (Silverthorne, 2004). Hence, this established the fact that employee's personality traits and organizational productivity have positive links. In addition, it also explains that the organizational productivity will be increased if there is a match between the employees' personal traits with the organizational culture. From the personality literature, some of the personality's theories that have been considered as the key theories are:

1. Psychoanalytic theories;

2. Humanistic theories;

3. Biological theories;

4. Behavioural, Social learning and Cognitive theories; and

5. Trait theories.

Among these five theories, trait theory is considered as one of the most accepted theory. It is also viewed as a leading personality theory that captures the significant elements that have high tendency to lead to certain behaviors. Ryckman (1997) meanwhile, categorized personality theories into five perspectives which are psychoanalytic, trait, cognitive, existential and social behaviouristic. The trait perspective assumed that there are dispositional factors that regularly and persistently determine conduct in a variety of everyday situations (Furnham, 1990). Ryckman, (1997) further stressed that in the cognitive perspective, people's personality is never completely determined as they are always changing and always free to reinterpret their experiences in idiosyncratic ways. Traits are defined by Tellegen (1991) as a psychological (therefore) organismic structure underlying a relatively enduring behavioral disposition, such as the individual tendency to respond in certain ways under certain circumstances.

However, this study utilized the big five personality theory which is also known as the "Big Five Model or Five Factor Model or FFM" as this theory has been considered as the highly accepted and widely known personality model from the last almost two decades. In addition, this model was also considered to be more appropriate in finding the answers to the research questions.

\section{Big Five Model}


The Big Five model was used by Khairul Anwar et al. (2000) to examine the personality and culture of the Malay community. 171 Malays who reside in Australia were chosen as this study respondents. This study indicated on the low level in the domains of Neuroticism and Extraversion. Meanwhile, the domains of Agreeableness, Conscientiousness are Openness to Experience were at higher stages in this Malay community. Salgado (2003) meanwhile compared the validity of the Big Five by considering five factor model (FFM) based and non-five factor model (FFM) based inventories. It was observed that the FFM-based inventories had high validity. Hence, it was suggested that the FFM should be used while assessing the performance of the employee.

Studies on personality and organizational outcomes have received enormous attention by researchers in the organizational behavior research. In their meta-analysis, Barrick and Mount (1991) examined five occupational groups; professional, police, managers, sales, skilled/semi-skilled and the three criteria of performance on job which were job aptitude and expertise, training aptitude and expertise, and personal records. In this study, Digman's (1990) personality terms and classifications which were extraversion, emotional stability, agreeableness, conscientiousness, and openness to experience were utilized. The worth mentioning result in the study is that the Conscientiousness was found to be a reliable and valid forecaster for all standard types and for all professional groups studied. Secondly for two professions, manager and sales, Extraversion was observed to be an effective forecaster. Ranked by supervisors in another meta-analysis, the Conscientiousness was also shown as an effective forecaster in the performance on the job (Frei \& McDaniel, 1998). In the case of Emotional Stability, the associations with performance on the job were found to be comparatively on the lower side. Perhaps one of the reasons, according to Barrick and Mount (1991) was that the extremely 'neurotic' persons are incapable to work successfully on their own and, this result to less possibility of including them in the labor force.

\section{Method}

A survey was used to find the relationship between personality traits with job satisfaction among teachers in Putrajaya secondary school. A set of questionnaires used in this study is adapted from The Big Five Inventory and Spector's Job satisfaction Survey developed by Spector's 1997, McCrae \& Costa, 1987. The data were analyzed by using descriptive data analysis was carried out to satisfy the first and second research objectives which were: "The Putrajaya Secondary School Teachers personality profile and The Putrajaya Secondary School teachers' level of job satisfaction. Accordingly, the degree of levels was identified as low, moderate and high. Then, three arbitrary levels were generated to summarize the total scores for both dependent and independent variables. Pearson's correlation to identify the relationship between variable.

The sample of the study comprises 150 secondary school teachers in Putrajaya. These 150 secondary school teachers in Putrajaya were selected randomly from the total of 600 secondary school teachers in Putrajaya. The target population for the study consisted of teacher in secondary school in Putrajaya. To date, there are currently eleven secondary schools in Putrajaya. As indicated two is the boarding school SMK Alam Shah and SMK Seri Puteri. 
INTERNATIONAL JOURNAL OF ACADEMIC RESEARCH IN BUSINESS AND SOCIAL SCIENCES

Vol. 9, No. 13, Special Issue: Revolutionizing Education: Challenges, Innovation, Collaboration., 2019, E-ISSN: 2222-6990 @ 2019 HRMARS

There are two kinds of secondary schools in Putrajaya, the daily schools and boarding schools. Both are under the jurisdiction of Ministry of Education. Teachers in this study are randomly selected from both kinds of schools. 160 questionnaires were sent out to five schools but only a total of 150 questionnaires were returned.

The questionnaires were distributed using the normal mail. The completed questionnaires were then mailed to the researcher using the self-envelope provided (table 1)

Table.1. Sampling distribution among the secondary teachers in Putrajaya

\begin{tabular}{llll}
\hline Secondary School & $\begin{array}{l}\text { Questionnaire } \\
\text { Distributed }\end{array}$ & $\begin{array}{l}\text { Frame } \\
(\%)\end{array}$ & $\begin{array}{l}\text { Proportion } \\
\text { Returned }\end{array}$ \\
\hline SMK Alam Shah & 32 & 90.63 & 29 \\
SMK Precint 11 & 32 & 87.50 & 28 \\
SMK Precint 8 & 32 & 93.75 & 30 \\
SMK Precint 16 & 32 & 100.0 & 32 \\
SMK Precint 9 & 32 & 96.88 & 31 \\
\hline & 160 & & 150 \\
\hline
\end{tabular}

\section{Results and Discussion}

Results are presented in tables on the type of personality traits, level of job satisfaction followed by the relationship between the variables.

Table.2. personality profiles of the Putrajaya Secondary School Teachers

\begin{tabular}{llll}
\hline & Mean & $\begin{array}{l}\text { Std. } \\
\text { Deviatio } \\
\mathbf{n}\end{array}$ & Rangking \\
\hline Personality profile & 2.88 & .53 & \\
Conscientiousness & 2.94 & .72 & 3 \\
Agreeableness & 3.03 & .60 & 1 \\
Openness & 2.94 & .56 & 2 \\
Extroversion & 2.76 & .61 & 4 \\
Neuroticism & 2.73 & .49 & 5 \\
\hline Mean score indicator: $1.00-1.33$ (Low), 1.34-2.33 (Moderate) and 2.34 - 4.00 (High)
\end{tabular}

Table 2 above findings show that the overall mean score for personality profile measures was high $(\mathrm{M}=2.88, \mathrm{SD}=.53)$ with the entailing five sub-variables; Agreeableness $(\mathrm{M}=3.03, \mathrm{SD}=.60)$, Openness $(\mathrm{M}=2.94, \mathrm{SD}=.56)$, Conscientiousness $(\mathrm{M}=2.94, \mathrm{SD}=.72)$. Extroversion $(\mathrm{M}=2.76, \mathrm{SD}=.61)$ and Neuroticism ( $M=2.73, S D=.49)$. Overall, respondents in this study represented a high mean for the five personality traits profile. As highest in Agreeableness is consider helpful, sympathetic and cooperative, compliant and moved by others (Costa and McCrae, 1992; Maltby et al., 2007), 
understanding and honest (Goldberg, 1990), good-natured, cheerful, caring and altruistic (Bernerth et. al, 2007). Ilies, Scott and Judge (2006) meanwhile, stated that an agreeableness individual would consistently help others An individual with high openness meanwhile, was claimed to have a high need for autonomy and tend not only to be creative and adaptive but was also accepting to change. Wright (2003), stated that an individual who registered in high conscientiousness trait, had a high sense of duty and obligation towards their work besides having high level of job performance, motivation, career success and job satisfaction. In addition, an individual with the dimension of conscientiousness was viewed as organised, orderly, precise and efficient (Harris and Flemming, 2005) while an individual with high extraversion was energetic, optimistic, friendly, spontaneous, like challenges, highly motivated, (Maltby et al., 2007; Robbins and Judge, 2007) sociable, gregarious, assertive, and talkative (Harris and Flemming, 2005; Kiritsis, 2014). In contrast to extrovert individual, introvert individual was perceived as someone who is reserved, independent and even-paced (Rothmann, 2003). Neuroticism which was another trait that scored high mean in this study refered to emotional stable and calm teacher who was able to face stressful situations in carrying out their job (Hough et al., 1990).

Table.3. Levels of job satisfaction of the Putrajaya Secondary School Teachers

\begin{tabular}{lc}
\hline Overall Job Satisfaction & $\begin{array}{l}\text { Valu } \\
\text { e }\end{array}$ \\
\hline Mean & 2.95 \\
Standard & .63 \\
Deviation & \\
Minimum & \\
Maximum & 1.52 \\
\end{tabular}

Mean score indicator: $1.00-1.33$ (Low), $1.34-2.33$ (Moderate) and $2.34-4.00$ (High)

Table 3 examined the level of job satisfaction of the Putrajaya Secondary School Teachers the mean value of 2.95 and the standard deviation of .63 for the overall result of the respondents' job satisfaction shows that in general, the respondents were highly satisfied with their job. This finding suggests that on the whole respondents were satisfied with their job as a teacher. In addition, the strong and good rapport among the teachers and their co-workers might also be the reason for job satisfaction amongst the staff to be increased (Saba, 2011; Crossman and Ahmad-Zaki, 2003). The finding of this research is also similar to the findings of earlier researches by Azumi and McMillan (1975), Fauziah (2000) and Fauziah and Anizah (2003) which indicated that the Asian workers were less contended with their work compared to the Western workers.Teachers' satisfaction towards their job might be due to the good human resource management practice in the schools organisation as this could also be one of the motivational factors that could influence and motivate these teachers in achieving the schools vision and mission (Othman et al., 2002; Asari, Hussin, \& Samsudin, 2018) 
INTERNATIONAL JOURNAL OF ACADEMIC RESEARCH IN BUSINESS AND SOCIAL SCIENCES

Vol. 9, No. 13, Special Issue: Revolutionizing Education: Challenges, Innovation, Collaboration., 2019, E-ISSN: 2222-6990 @ 2019 HRMARS

Table.4. Relationship between personality traits and job satisfaction among secondary school teacher in Putrajaya.

\begin{tabular}{|c|c|c|c|}
\hline & & \multicolumn{2}{|c|}{ PersonalityJob } \\
\hline & & Traits & Satisfaction \\
\hline Personality & $\begin{array}{l}\text { Pearson } \\
\text { Correlation }\end{array}$ & 1 & $.957^{* *}$ \\
\hline \multirow[t]{3}{*}{ Traits } & Sig. (2-tailed) & & .000 \\
\hline & $\mathrm{N}$ & 150 & 150 \\
\hline & $\begin{array}{l}\text { Pearson } \\
\text { Correlation }\end{array}$ & $.957^{* *}$ & 1 \\
\hline \multirow[t]{2}{*}{ Satisfaction } & Sig. (2-tailed) & .000 & \\
\hline & $\mathrm{N}$ & 150 & 150 \\
\hline
\end{tabular}

Statistically, correlation refers to a relationship between two variables which might assist in measuring the depth of the relationship and ultimately drew a testable conclusion about the population. The most widely used type of correlation coefficient is Pearson $r$, which is also known as the linear correlation. The linear correlation was run to analyze the correlation between personality traits and job satisfaction. From Table 4. Above, the analysis indicated that there is a positive relationship between personality traits and job satisfaction $(r=.957, p<0.01)$. The analysis also indicated that there is strong correlation between the job satisfaction and personality traits and a significant relationship between personality traits and job satisfaction at the point 0.05 . This finding was in line with studies done by Abdullah (2002); Santhapparaj and Alam (2005) .

\section{Conclusions}

The findings revealed that most secondary school teachers in Putrajaya are satisfied with their jobs. According to Spector, 1997, Job satisfaction was referred to the influenced people's attitude towards their jobs and various aspect of their jobs, therefore this shows that the teachers have the right attitude towards their jobs. In this study, the result showed that among the nine subscales in the questionnaires the parts of salary, promotion and communications dominated in the aspect of job satisfaction in general. The satisfaction the teachers felt is probably due to the announcement made by Ministry of Education, introducing the time based promotion system, also a total of 24,053 teachers who had completed the required duration of service will be considered for promotion ( New Straits times, March 2012). The report stated that the Ministry of Education had improved on Malaysian Remuneration Scheme (SSM) for civil servants, which came with a 13 per cent pay rise. Besides, communication was also another important aspect in job satisfaction. Workers, who could communicate with their leaders and subordinates, were prone to find that they are satisfied with their job and may induce less job stress for the worker.

The finding revealed that the nature of personality traits among secondary school teachers were high. Personality played an important role in the way of thinking, feeling and relating to other people. To become excellent teachers especially when encountering challenges and complex work, teachers 
need and have positive attitude. The result showed that the sub-scales in personality traits which were openness, agreeableness and conscientiousness showed high mean scores. According to Daft, (2002) openness was the degree to which a person has a broad range of interests and was imaginative, creative and willing to consider new ideas. Conscientiousness refers to the degree to which a person was responsible, dependable, persistent and achievement-oriented. The dimension of agreeableness is the degree in which an individual is affable, tolerant, sensitive, trusting, kind, and warm. Thus, the finding could be inferred that the respondents' personalities to some degree of extend were open to new ideas, responsible, achievement oriented, warmth and kind. This reflected a positive attitude among teachers' personality traits in Malaysia. According to Ferrett (1994), the key success at work was a positive work attitude and workers with such attitudes and who are enthusiastic at work have become invaluable to present organizations.

The final research objective of the study was intended to examine the relationship between personality traits and job satisfaction. This study revealed indeed a surprising result where there was a positive and high relationship between personality traits and job satisfaction. This finding suggested that job satisfaction could be influenced by high personality traits. This finding was in line with the study done by Sutin et al (2009); Anghel, Anghelache, Dumitrescu, Burea, Stoica, (2018). However, Sutin and Costa (2008) asserted that monetary reward, rather than the job subjective evaluation or the environmental working conditions, contributed to personality development in adulthood. Nevertheless, Staw, Bell, and Clausen (1986) revealed that the individual with positive job satisfaction is the person who held positive emotion towards their job.

In summary, the study provided there is a significant relationship between personality traits and job satisfaction among secondary teacher in Putrajaya. The findings have shown that the overall mean score for personality profile measures was high $(M=2.88, S D=.53)$ with the entailing five subvariables; Agreeableness ( $M=3.03, S D=.60)$, Openness $(M=2.94, S D=.56)$, Conscientiousness ( $M=2.94$, $\mathrm{SD}=.72)$. Extroversion $(\mathrm{M}=2.76, \mathrm{SD}=.61)$ and Neuroticism scored mean $(\mathrm{M}=2.73, \mathrm{SD}=.49$.)

The findings in this study illustrated that teachers' satisfactions towards their jobs might be strongly influenced by the type of co-worker's personality available in their schools. In addition, promotion and pay were also the other two factors that could influence teachers' job satisfaction. Thus, having co-workers with the right personalities might significantly enhance teachers' performance and job satisfaction. The analysis further showed that operation condition and supervision with the mean score 2.82 and 2.77 were the least factors that influenced teachers' job satisfaction.

Summary of the findings showed that the respondents strongly agree that job satisfaction might be strongly affected by their co-workers. In addition, promotion and pay might also be another factor affecting job satisfaction. Thus, having effective co-workers in the school might significantly enhanced the teachers' performance and job satisfaction. Nevertheless, this research highlights that teachers' job satisfaction was influenced by their individual personality traits. Other factors such as co-worker, promotion and pay could also play significant relationship in fulfilling teachers' satisfaction toward their own job. 


\section{References}

AnghelM, G., Anghelache, C., Dumitrescu, D., Burea, D., Stoica, R. (2018). Analysis of the Effect of Accessing the Community Funds for Financing Investments on Romania's Economic Growth, International Journal of Academic Research in Accounting, Finance and Management Sciences 8 (2): 102-112.

Asari, S. I. I. S., Hussin, N., \& Samsudin, A. Z. H. (2018). International Best Practices Analysis of Metadata Standard and Guidelines for the Development of Electronic Health Recordkeeping Metadata Standards of Malaysian Government Hospital System Integration. International Journal of Academic Research in Progressive Education and Development, 7(3), 247-257.

Alexander, J. A., Liechtenstein, R. O., \& Hellmann, E. (1998). A causal model of voluntary turn-over among nursing personnel in long term psychiatric setting. Research in Nursing and Health, 21(5), 415-427

Santhapparaj, A. S., Alam, S. S. (2005) Journal: job satisfactions: Journal of Social Sciences ISSN/EISSN: 15493652 Year: 2005 Volume: 1 Issue: 2 Pages: 72-76S.

Arnold and Feldman. (1986) defined job satisfaction. Trait Names: A Psycho-lexical Study. Psychology Monographs. 47(211), 171-220.

Ashkanasy, N., Wilderom, C., \& Peterson, M. (Eds.). (2000). Handbook of Organizational Culture andClimate.Thousand Oaks, CA: Sage. Schein, E.H. Organizational culture and leadership Jossey-Bass, San Francisco, 1985.

Barrick, M. R., Stewart, J. L., \& Piotrowski, M. (2002). Personality and job performance: test of the mediating effects of motivation among sales representatives. Journal of Applied Psychology. Feb, 87(1), 43-51.

Beer, A., \& Brooks, C. (2011). Information quality in personality judgment: The value of personal disclosure. Journal of Research

Bolarin, T. A. (1993). Late payment of teachers' salary as it affects the quality of education in Lagos state primary schools: A socio-psychological perspective. Journal of National Association of Education Teachers, 6(1), 11-15 coaching behaviors and group cohesion in high school football teams. The Sport Psychologist, v. 5, p. 41-45,1991.

Brown, J., \& Sheppard, B. (1997). Teacher librarians in learning organizations. Paper Presented at the Annual Conference of the International Association of School Librarianship, Canada. August 25-30

Borman, D. R. I., \& Klimoski, R. J. (Eds.), Handbook of psychology (Vol. 12, pp. 255-276). Hoboken, NJ: Wiley

Barrick, M. R., \& Mount, M. K. (2000). The Big Five personality dimensions and job performance: A Meta-Analysis. Personnel Psychology. 41, 2-50.

Barrick, M. R., \& Mount, M. K. (1993). Autonomy as a moderator of the relationships between the Big Five personality dimensions and job performance. Journal of Applied Psychology. 78, 111-118.

Bandura, A. (1971). Social Learning Theory. General Learning Press, Morristown, NJ.

Benet-Martınez, V., \& John, O. P. (1998). Los Cinco Grandes: Across cultures and ethnic groups: Multitrait-multimethod analyses of the Big Five in Spanish and English. Journal of Personality and Social Psychology, 75, 729-750. 
Barrick, M. R., \& Mount, K. M. (2005). Yes,Personality Matters: Moving on to More Important Matters. Human Performance,18(4), pp. 359-372.

Cronbach, L.J., Glaser, G.C., Nanda, H. \& Rajaratnam, N. (1972). The dependability of behavioral measurements: Theory of generalizability for scores and profiles. New York: Wiley.

Cattell, Raymond B., Cattell, \& Heather E. P. (1995). Personality structure and the new fifth edition of the 16PF. Educational and Psychological Measurement, 55(6), 926-937.

Chatzoglou, P. D., Vraimaki, E., Komsiou, E., Polychrou, E., \& Diamantidis, A. D. (2011). Factors Affecting Accountants' Job Satisfaction and Turnover Intentions: A Structural Equation Model. 8th International Conference on Enterprise Systems, Accounting and Logistics (8th ICESAL 2011), 11-12 July 2011, Thassos Island, Greece.

Costa, Jr P.T. R., and Eaton, W. W. (2009) Personality and Career Success: Concurrent and Longitudinal Relations.Eur J Pers. 2009 March 1; 23(2): 71-84.

Chicago: Rand McNally. Maslow, A. H. (1943). A theory of human motivation. Psychological review, 370-396

Dweck, C. S. (1999). Self-theories: Their role in Motivation, Personality, and Development. Philadelphia, PA: Psychology Press

Karim, F. (1999). The development of single trait personality theories. Personality and Individual Differences, 11, 923-9.

Nordin, T. A. (1992). Pendidikan dan Wawasan 2020. Kuala Lumpur: Arena IImu

Kiritsis, D. (2014). Educational Aims and Professional Fulfillment. Multilingual Academic Journal of Education and Social Sciences, 2(1), 57-66.

Salaudin, A. K., Mohamed, M., \& Kamal, A. A. (2019). The Relationship Between Personality Traits and Job Satisfaction Among Secondary School Teachers in Putrajaya. International Journal of Academic Research in Business and Social Sciences, 9(13), 360-371. 